NBER WORKING PAPER SERIES

\title{
CROSS COUNTRY FAIRNESS CONSIDERATIONS AND COUNTRY IMPLICATIONS OF ALTERNATIVE APPROACHES TO A GLOBAL EMISSION REDUCTION REGIME
}

\author{
Huifang Tian \\ Xiaojun Shi \\ John Whalley \\ Working Paper 18443 \\ http://www.nber.org/papers/w18443
}

\author{
NATIONAL BUREAU OF ECONOMIC RESEARCH \\ 1050 Massachusetts Avenue \\ Cambridge, MA 02138 \\ October 2012
}

We are grateful to the Ontario Research Fund and CIGI for financial support. Huifang Tian is also grateful for support from the Specialized Research Fund by CASS-IWEP and Renmin University of China. The views expressed herein are those of the authors and do not necessarily reflect the views of the National Bureau of Economic Research. Xiaojun Shi is grateful to National Natural Science Fund of China (Projects Nos. 70972001, 71172014 ) for financial support.

NBER working papers are circulated for discussion and comment purposes. They have not been peerreviewed or been subject to the review by the NBER Board of Directors that accompanies official NBER publications.

(C) 2012 by Huifang Tian, Xiaojun Shi, and John Whalley. All rights reserved. Short sections of text, not to exceed two paragraphs, may be quoted without explicit permission provided that full credit, including $\odot$ notice, is given to the source. 
Cross Country Fairness Considerations and Country Implications of Alternative Approaches

to a Global Emission Reduction Regime

Huifang Tian, Xiaojun Shi , and John Whalley

NBER Working Paper No. 18443

October 2012

JEL No. F00,Q54,Q56

\begin{abstract}
The UNFCCC process of negotiating multilateral carbon emissions reductions thus far has focused on approximately equiproportional cuts in annual carbon emissions by country along the lines of the Kyoto Protocol agreement. But now, with the objective of involving large developing countries such as China and India in a post 2012 regime, broader considerations imply alternative approaches to emissions reduction arrangements by countries be considered. Here we consider the implications of alternative cross country fairness considerations entering the global negotiation process using a numerical simulation model which captures the potential impacts of alternative emission reductions across major economies which in turn reflect different fairness arguments. We put other fairness considerations, such as intergenerational equity, on one side. We use a global equilibrium emissions and trade model with transfers which are calibrated to a 2005-2050 BAU scenario and treats damage from climate change as utility damage. It thus captures the benefit side of emissions reduction agreements as well as the implications of such considerations for financial transfers agreed as a part of the process. Our analyses consider four alternative justices formulations. One is equal per capita allocation of absorptive capacity of the atmosphere given a temperature change target for global emissions. Yet another is where cuts by countries yield equal benefits per capita to other countries. A third is where there are equal costs per capita to countries making cuts. Finally, we also consider financial transfers to developing countries to compensate them for the costs of meeting emission restraints. The impacts of alternative emissions reductions differ sharply from the equi-proportional cuts of annual emissions implied by a continuation of the Kyoto process. These impacts emphasize the large and ill defined bargaining set for a post Kyoto Process involving large developing countries in a significant way.
\end{abstract}

\author{
Huifang Tian \\ IWEP, Chinese Academy of Social Sciences \\ Centre for International Governance \\ Innovation (CIGI) \\ University of Western Ontario \\ tianhf@cass.org.cn \\ Xiaojun Shi \\ School of Finance \\ Renmin University of China \\ Beijing, 100872, P.R. China \\ sxjstein@yahoo.com.cn
}

\author{
John Whalley \\ Department of Economics \\ Social Science Centre \\ University of Western Ontario \\ London, ON N6A 5C2 \\ CANADA \\ and NBER \\ jwhalley@uwo.ca
}




\section{Introduction}

The proposals for carbon emission reductions by country that were made during the various UNFCCC COP meetings over the period 2008-2012 for the post 2012 period after present arrangements under the Kyoto protocol expire have been based largely on equal proportional reductions in annual emissions by countries of greenhouse gases measured in carbon equivalent terms. These proposed cuts were seen as simple and based on apparent similar treatment to all. It was seemingly assumed by major participant developed countries that the main point of contention remaining was the depth of cuts.

The cuts resulting from this approach have, however, been vigorously opposed by developing countries who fear that such commitments will truncate their development, and emphasize how the "common but differentiated responsibility" declaration in the United Nations Framework Convention on Climate Change (UNFCCC) gives them rights to special treatment. Countries who have only recently industrialized, such as China and India, have also argued that cumulative, not annual emissions should be used. And they have also argued that historical emissions should be taken into account and differential impacts implied by their high growth rates be taken into account.

The implied departures from equiproportional reductions increase further if other fairness arguments are allowed. Countries with large resource producing industries can also claim larger than average adjustments will ensure for them, and hence they should receive special treatment. Economies with lax migration policies and hence growing populations can claim that allowance should be made for their changing numbers. And countries with already high excise taxes on gasoline and fuels can argue their case for smaller reductions.

While the negotiating process has seemingly reached on impasse in Durban in cuts 2011 there remains a commitment to continued negotiation out to 2015. Here, in light of this commitment, we assess the potential implications of adopting various concepts of cross country fairness as the basis for country cuts in a post Kyoto regime, rather than appealing to the simplicity of equiproportional reductions. We develop several inter-related equity notions to explore their implications in a global emission reduction model capturing both costs and benefits of reductions. One uses the global emissions reductions implied by equal 
per capita allocation of the emissions constraint on the absorptive capacity of the atmosphere given a target for global temperature change by a specific date. This allocation may or may not take into account historical emissions. Another appeals to reductions which yield equal benefits to other country residents per capita for countries making reductions, yet other appeals to equal costs per capita for countries making costs. We also consider transfers from richer developed countries that compensate poorer developing countries for losses incurred by them when taking on climate policies commitments. These losses can be thought of as forgone development opportunities for them from emission countries limitations.

We use numerical simulation methods and our results show sharp departures in country impacts from the equi proportional reductions discussed thus far in UNFCCC negotiations, and produce a wide range of outcomes. From these results we draw the conclusion that the bargaining set for the post Kyoto, post 2012, post Durban process is likely large. This continues to point to a complex and difficult to conclude negotiation.

\section{Cross country fairness and the post Durban process for a global climate regime}

Appealing to fairness considerations in the ways in which Post Kyoto Climate change policy regime evolves will likely be a central element in the discussions to follow after the Durban meeting in December 2011 and the end of the Kyoto period of reductions. The aim of negotiations had been to agree a global policy regime to follow on after in 2012 from the earlier 1997 Kyoto Protocol. Only a minimal platform agreement resulted from this process in the 2009 Copenhagen accords. Further progress seemingly involves the resolution of a series of issues which were not touched on in any depth in Copenhagen and subsequent meetings, but which directly follow from arguments involving fairness or justice cross countries.

These include emissions reductions based on annual versus cumulative emissions, the allocation on a per capita basis of a global constraint on emissions consistent with a temperature change target and how historical emissions enter such allocations. Also arising are the interpretation of the Common but Differentiated Responsibilities (CBDR) commitment in the UNFCCC for developing countries; the use of a consumption or production basis for emissions reductions; the use of level or intensity targets for emissions 
reductions; the choice of a base date for calculating reductions; the length of commitment period; the depth of cut and the implied temperature change target; the form and size of accompanying financial arrangements; and the allowable use of accompanying border adjustments.

In Copenhagen and subsequent UNFCCC meetings and the run up to them, these issues were not centrally discussed, but they remain key to the emergence of any agreed post Kyoto global climate framework. Justice or fairness notions in debates on resolution of these issues can be made in abstract form largely independently of the constraints implied by agreements already entered into the UNFCCC; or can be applied considering the constraints over the bargaining set already agreed to in a form of prior agenda formulation negotiations. Here we link to cross country fairness agreements, putting other dimensions of fairness (such as intergenerational equity) on one side.

Justice in economic decision making is one of the perennial themes in philosophy (ethics) tracing back at least to Aristotle, and there is a large amount of work which can be drawn on among which Rawls (1971) is perhaps one of the best known. In Rawls's, justice theory condenses into two key theorems. One is the difference rule, which implies maximizing the well-being of the worst off member of society. Applying this to the post Kyoto negotiation process (using Beitz's (1979) corollary of Rawls' justice in the international sense), one could argue for justice based arrangements on two levels. On the first, those countries most vulnerable to climate changes should be compensated for damage incurred but not caused their own emissions. This could take the form of exemptions for cost burdens of global policies to combat climate changes in the future. On a second level, the developing world as a whole claim compensation in the long run for combating climate change, via financial aid and subsidized clean energy technology transfer from the developed world to offset forgone development.

More recent economics literature also contributes to justice debates using new formulations. A central issue is the definition of fairness. At the heart of these analyses is a description of a stable state as one in which no one is willing to change his own wealth (consumption) by changing positions with others, i.e., relative fairness. Using to this relative fairness concept, Fehr and Schmidt (1999) define a utility function for climate change 
embedded with fairness. Fairness in this case is defined as an unfairness aversion coefficient times the minimum of the difference between what the agent and his peer in society are offered, and zero. The discussion of this in Kirman (1999) seemingly rejects the equiproportional burden-sharing mechanisms of the Kyoto process and suggests that developed and developing countries should not be treated on the same basis, since the implied initial allocation of usable atmosphere for development is unfair.

We use four alternative notions of cross countries fairness in model based analyses of the potential impacts of alternative emissions reductions proposals and financial transfers. One is to allocate scare atmospheric capacity in meeting targets for global temperature change on an equal per capita basis across countries. This can be done either on the basis of remaining atmospheric capacity at a point in time, or on the basis of remaining capacity net of historical usage by countries. Another is to use country reductions which yield benefits to other countries such that the costs per capita for countries making the reductions are the same. One can also consider the financial transfers between developed and developing countries under each approach which compensates developing countries for forgone development opportunities due to emission reductions.

In an earlier paper, Tian and Whalley (2010) used equilibrium computational methods to analyze the country and global impacts of post Kyoto proposed multilateral emission reductions, accompanying financial transfers and trade based measures reflecting actual proposals made during negotiation. There was an 8 country calibrated equilibrium structure which used a base data of 2006 out to either 2020 or 2030 as a single BAU base period and with climate change benefits captured directly in preferences. Their results indicated large country variation in country impacts of alternative equiproportional reduction formula (such as using annual or cumulative emissions), as well as the need for significant financial transfers to non OECD countries (China, India, Brazil) to induce their participation. They also explored the role which could be played indirectly by the use of trade measures by OECD countries against non participant (presumably non OECD) countries.

We use a similar calibrated equilibrium model to analyze the impacts of alternative emission reductions, financial transfers, and border measures based on the alternative notions of fairness indicated above. We discuss what these alternative approaches suggest 
for country participation in three components of global environmental negotiations: mitigation, adaptation (financial transfers), and trade measures. As we sequentially apply these alternative notions, what emerges is that the bargaining set for the Post Copenhagen negotiation seems ever widening, highlighting further the large difficulties in concluding a global climate negotiation. The precise size and dimensions of the bargaining set remain inevitably highly uncertain due to the further ambiguities of which analytical construct to use to analyze the potential countries or region impacts of emissions reductions as well as the ambiguities of which functional forms and parameter values to use in judging alternative outcomes.

In performing our analyses we adopt of a target for global climate change regime not to exceed 2 degree temperature change by 2050. Reports of the Intergovernmental Panel on Climate Change (IPCC) suggest there is no specific temperature threshold for dangerous climate change, and negative effects are gradually increasing, but over one hundred countries have adopted this " $2{ }^{\circ} \mathrm{C}$ target". Two recent studies by a group of German, Swiss and British researchers in the journal Nature (Meinshausen et al. 2009, Allen et al. 2009) also suggest that, to contain global warming, and its risks and consequences, warming related to pre-industrial times (pre 1900) should not exceed two degrees Celsius. These two studies published in Nature suggest that from 2000 to 2050 in meeting a $2^{\circ} \mathrm{C}$ target, a maximum of 1000 billion tones of $\mathrm{CO} 2$ may be emitted into the atmosphere. Around one third of this has already been emitted. If emission remains at current levels, or even increase, the global emissions budget would be exhausted by $2030^{2}$. These calculations suggest that the time to act remains short and cross country fairness considerations seemingly must inevitably enter the debate on how to do it.

\section{A Modeling Framework for the Evaluation of the Impacts of Cross Country Fairness Considerations in Post 2012 Emissions Reduction Arrangements}

To analyze the potential impacts of the various alternative global arrangements based on fairness considerations, we have adapted a modeling framework used earlier by Cai,

\footnotetext{
${ }^{2}$ Nordhaus (2010) reports similar results: his cumulative emissions target for 2055 is 376.73 GTC (equivalent 1382.60 billion tones of $\mathrm{CO}$ ) for limiting global warning to $2 \mathrm{C}$
} 
Riezman, and Whalley (2009) and Tian and Whalley(2010) to analyze linkages between trade, trade policy and climate change arrangements under Kyoto type arrangements. Here we elaborate on this framework and use it to evaluate the impacts of alternative potential emissions reductions which take fairness into account. We focus on impacts on the large population rapidly growing developing economies of China, India, Russia and Brazil. We also explore the impacts of border taxes, tariffs, and/or transfers as part of equity motivated packages.

\subsection{Modelling Temperature Change and Top Level Country Utility Functions}

We analyze a single period of a number of years during which each of a number of large national economies is assumed to grow at a constant compounding rate ${ }^{3}$. Each country in the period is assumed to be able to consume or export one country heterogeneous good whose potential consumption (or use) grows at this rate in the base case. We assume that consumption of the good either by the country directly or by others through trade generates emissions of carbon which in turn raise global temperature. Countries have an upper bound on the use of their own good reflecting a Business as Usual (BAU) scenario. If they use (consume or export) less than the upper bound, they experience less temperature change as do all other countries. Countries receive positive utility from consumption, but negative utility from temperature change. Countries export their own good and import other country goods. If countries are small, their own actions have little or no effect on temperature change. The amount of resources needed to be put aside to achieve given reductions reflects abatement cost estimates.

As we later work with the impacts of agreements which reduce carbon emissions over a given period of time, we use a single period from 2012 out to 2020, 2030 or 2050. These reflect possible commitment periods for a global agreement on a post 2012 regime. In this multi year period, we focus on changes in consumption (use of own and foreign goods) and

\footnotetext{
${ }^{3}$ Because the model uses a single period, discounting does not formally enter the analytic structure. Discounting does, however, arise with the use of a discount rate in calculating the discounted present value of GDP over the model period. We consider cases with a common discount rate of $1 \%$ across all countries in sensitivity analysis, since the growth rates of key OECD countries (EU, Japan) are low. See also the discussion of discounting and climate change policy in Weitzman (2007) and Dasgupta (2008), and the key role discounting plays in the conclusions of the Stern (2006) report.
} 
utility, and measure changes in these variables relative to the outcome of zero growth over the period. We report changes in utility in money metric (Hicksian) form in US\$ amounts.

The utility impacts of possible reduction agreements for each country over the period is reflected in a utility change function relative to utility under zero growth, with arguments given by the own country change in a composite of consumption as well as the temperature change of the world. The utility function is thus defined over multiyear changes in consumption and temperature. The potential use of each country good thus reflects changes in potential output from the economy over the same period.

We first analyze a business as usual (BAU) scenario which assumes current observed growth rates remaining unchanged over the model period, and with no global or single country emissions limitation initiatives in place. We initially assume the utility change function for each country has the form

$$
\Delta U^{i}=\Delta U\left(\Delta C_{i}, \Delta T\right)=\Delta C_{i} *\left(\left(\frac{H-\Delta T}{H}\right)\right)^{\beta}
$$

In this specification, $\Delta C_{i}$ represents the change in consumption for each country $\mathrm{i}$ over the period. This is a composite of their own good and other country's goods which they acquire by importing other country's goods and exporting their own good. This provides a link between trade, tariffs and emission reduction incentives which we use to also explore the possible impacts of accompanying trade measures for a post 2012 arrangement.

In this, $\mathrm{H}$ can be thought of the global temperature change at which all economic activity ceases (say $20^{\circ} \mathrm{C}$ ). As $\Delta \mathrm{T}$ approaches $\mathrm{H}$, utility change goes to zero and $\Delta \mathrm{T}$ goes to zero and there is no welfare impact of temperature change. Utility change over any model period increases as temperature change falls.

The share parameter $\beta$ determines the severity of damage (in utility terms) from any given temperature change. We later calibrate the model to various damage estimates from business as usual global temperature change reported by Stern (2006) and Mendelsohn (2007), and this procedure determines $\beta$. For simplicity, we assume $\beta$ is the same value across countries.

Global temperature change, in turn, is determined by the change in carbon emissions over the period across all countries in the model. We adopt a simple global temperature 
change function and assume that emissions by each country equal the change in consumption times country emissions intensity (emissions/GDP) so as to allow for differing emissions intensities by country. Defining the emissions intensity of country $i$ as $e_{i}$, we use a power function (2) to capture global temperature change due to changes in emissions by all countries over the model period.

$$
\Delta T=g\left(\sum_{i} e_{i} \Delta S_{i}\right)=a\left(\sum_{i} e_{i} \Delta S_{i}\right)^{b}+c
$$

where $\Delta S_{i}$ represents the change in the use (consumption plus exports) of the own good for each country i. ${ }^{4}$ In the central case formulation of the model, $e_{i}$ is exogenous and fixed at its 2006 base case level. Consumption of each country good by all countries is less than or equal to $\Delta \mathrm{S}_{\mathrm{i}}$; and $\Delta \mathrm{S}_{\mathrm{i}}$ is less than or equal to the upper bound $\overline{\Delta S_{i}}$ associated with the base case scenario since countries can choose whether to participate in emission reductions initiatives. The typical scenario we consider is where countries in the model can commit to

emission reductions which are a given percentage of their $\overline{\Delta S_{i}}$. We also conduct sensitivity analyses in which the $e_{i}$ change over time to reflect increased efficiency of energy use over time. Finally we consider accompanying trade and finance mechanisms under which developing countries have the option of joining a negotiated percentage reduction (and also possibly receiving transfers) or not joining and forgoing the transfer(and possibly facing border adjustments and/or tariffs).

\subsection{Composite consumption by country}

In this model structure, a carbon reduction commitment by a single country implies a reduction in composite consumption (a composite of the country specific goods reflecting international trade), and this has both negative and positive effects on utility change for all countries over the model period. On the one hand, a reduction in consumption lowers utility for the consuming country. But on the other hand, country consumption reductions lower global emissions and hence world temperature change, and increases the utility both of the

\footnotetext{
${ }^{4}$ Ideally, this power function should have the property that there is increasing marginal impact on temperature change for progessive increases in consumption, i.e., $b>1$. We however calibrate this function to estimates of temperature change of $3^{\circ} \mathrm{C}$ by 2030 and $5^{\circ} \mathrm{C}$ by 2050 given in the Stern (2006) report, which jointly implies $b<1$.
} 
country reducing emissions and all other countries.

The composite consumption good $C_{i}$ is a CES function of domestic and imported consumption goods, similar to that used in nested CES Armington trade models (see Whalley (1985)). The model is thus effectively an Armington $\mathrm{N}$ good $\mathrm{N}$ country pure trade economy in which the endowment is variable.

The $C_{i}$ are determined by solving the country optimization problems.

$\operatorname{Max} C_{i}=C_{i}\left(D_{i}, M_{i}\right)=\left(\left(\lambda_{1}^{i}\right)^{\frac{1}{\sigma}} D_{i}^{\frac{\sigma-1}{\sigma}}+\left(\lambda_{2}^{i}\right)^{\frac{1}{\sigma}} M_{i}^{\frac{\sigma-1}{\sigma}}\right)^{\frac{\sigma}{\sigma-1}}$

s.t. $p_{i}^{w} D_{i}+p_{i}^{m} M_{i} \leq I_{i}=p_{i}^{w} S_{i}$

where $D_{i}$ and $M_{i}$, in turn, represent consumption of the domestic good and a composite imported good respectively with $p_{i}^{w}$ and $p_{i}^{m}$ as their prices, $\lambda_{1}^{i}$ and $\lambda_{2}^{i}$ as the consumption shares, and $\sigma$ as the substitution elasticity ${ }^{5}$.

Demands for domestic consumption goods and imported composite consumption goods are:

$$
\begin{aligned}
& M_{i}=\frac{\lambda_{2}^{i} I}{\left(p_{i}^{m}\right)^{\sigma}\left(\lambda_{1}^{i}\left(p_{i}^{w}\right)^{(1-\sigma)}+\lambda_{2}^{i}\left(p_{i}^{m}\right)^{(1-\sigma)}\right)} \quad(\mathrm{i}=1 \ldots \mathrm{N}) \\
& D_{i}=\frac{\lambda_{1}^{i} I}{\left(p_{i}^{w}\right)^{\sigma}\left(\lambda_{1}^{i}\left(p_{i}^{w}\right)^{(1-\sigma)}+\lambda_{2}^{i}\left(p_{i}^{m}\right)^{(1-\sigma)}\right)} \quad(\mathrm{i}=1 \ldots \mathrm{N})
\end{aligned}
$$

The composition of $M_{i}$ is determined by a third level of nesting in the model, and $p_{i}^{m}$ is a price index of seller's prices $p_{i}^{w}$ (see equation (9)). $I_{i}$ is country income and is given by sales of own good $S_{i}$ at the world price $p_{i}^{w}$. Unlike in a conventional Armington trade model, $S_{i}$ is endogenous and also the outcome of a discrete choice optimization problem involving participation or non participation in proposal climate change agreements.

\subsection{Composites of Imported Goods}

The CES import composites $M_{i}$ are composites of imported goods from each supplying country. Given that each country has one good it can sell, but N-1 goods it imports,

\footnotetext{
${ }^{5}$ We use the same central case settings of elasticities as Cai, Riezman and Whalley (2009) of $\sigma=0.5$ and $\sigma_{m}=0.9$ Cai et al provide literature based discussion of these values, which we later vary in sensitivity analysis.
} 
the CES composite of other goods define the import composite, and is the outcome of a sub-utility maximization problem

$$
\begin{array}{ll}
\operatorname{Max} & M_{i}=H\left(R_{1}^{i}, R_{2}^{i}, \ldots, R_{i-1}^{i}, R_{i+1}^{i}, \ldots, R_{N}^{i}\right)=\left(\sum_{j \neq i}\left(\kappa_{j}^{i}\right)^{\frac{1}{\sigma_{m}}}\left(R_{j}^{i}\right)^{\frac{\sigma_{m}-1}{\sigma_{m}}}\right)^{\frac{\sigma_{m}}{\sigma_{m}-1}} \\
\text { s.t. } & \sum_{j \neq i} p_{j}^{d_{i}} R_{j}^{i} \leq I_{i}^{m}=p M_{i}^{M}
\end{array}
$$

where $R_{j}^{i}$ is the country good $\mathrm{j}$ imported by country $p_{i}^{m}$ is the composite import price for country $\mathrm{i}, \kappa_{j}^{i}$ is the consumption share and $\sigma_{m}$ is the second level substitution elasticity. $I_{i}^{m}$ is the income devoted to expenditures on imports (from (6)). These CES sub-utility maximizations give:

$$
\begin{aligned}
& p_{i}^{m}=\left[\sum_{j \neq i} \kappa_{j}^{i}\left(p_{j}^{d_{i}}\right)^{1-\sigma_{m}}\right]^{\frac{1}{1-\sigma_{m}}} \\
& R_{j}^{i}=\frac{\kappa_{j}^{i} p_{i}^{m} M_{i}}{\left(p_{j}^{d_{i}}\right)^{\sigma_{m}} \sum_{j \neq i} \kappa_{j}^{i}\left(p_{j}^{d_{i}}\right)^{1-\sigma_{m}}}=\frac{\kappa_{j}^{i}\left(p_{i}^{m}\right)^{\sigma_{m}} M_{i}}{\left(p_{j}^{d_{i}}\right)^{\sigma_{m}}}
\end{aligned}
$$

\subsection{Trade and climate change Equilibrium}

Given values of $\Delta S_{i}$, a trade equilibrium is given by prices $p_{1}^{w}, \ldots, p_{N}^{w} \square$ for which global markets clear, i.e.

$$
\sum_{j \neq i} R_{i}^{j}+D_{i}=\Delta S_{i} \quad(i=1 . N
$$

The $\Delta S_{i}$ take on the values $\overline{\Delta S_{i}}$ in the base case and one of two values in counterfactual analyses. $\Delta S_{i}$ can be the implied reduction in $\overline{\Delta S_{i}}$ for countries meeting emissions reduction commitments. Alternatively, $\Delta S_{i}$ is equal to $\overline{\Delta S_{i}}$ for non OECD countries if they do not participate.

In this structure, when countries participate in a global climate agreement, if they reduce emissions by reducing GDP there will be general equilibrium implications for all prices and quantities. Importantly, if there are accompanying mechanisms, tariffs against countries will cause the price of their own good $i$ to fall giving a terms of trade loss for the country not making the emissions reduction. This will, in turn, increase the willingness of countries to 
participate in global emission reductions negotiations. Transfers do not exert this direct term of trade effect through a relative price intervention, but as countries receiving transfers spend most of their income on their own good, in the calibrated Armington structure a terms of trade effect will come into play through income effects.

\subsection{Costs of Mitigation}

A further element in the model is the cost of mitigating damage from climate change through emission reduction, or abatement costs. We capture these in a simple mitigation cost function where country mitigation costs are a linear constant marginal cost function of use of own good (consumption plus export). Stern (2006) places these costs at $1 \%$ of GDP \pm $3 \%$ for a $50 \%$ reduction in emissions by 2050 . We use a central case estimate of $2.5 \%$ and then use sensitivity ranges for this key parameter. The mitigation (abatement) cost function is;

$$
M C_{i}=\varphi \frac{\left(\overline{\Delta E_{i}}-\Delta E_{i}\right)}{\overline{\Delta E_{i}}} S_{i}
$$

where $M C_{i}$ are the mitigation costs of country $i$ for emissions mitigation of an amount given by $\left(\overline{\Delta E_{i}}\right.$ (base case) $-\Delta E_{i}$ (new emission)). $\Delta E_{i}$ are the new emissions implied by the reduction and $\overline{\Delta E_{i}}$ are the emissions changes along the BAU path. $\frac{\left(\overline{\Delta E_{i}}-\Delta E_{i}\right)}{\overline{\Delta E_{i}}}$ is thus the proportional change in emissions. $\varphi$ is the emission reduction cost factor linking the proportional change in emissions to use of resources. We set $\varphi$ equal to 0.025 in the base case, and conduct sensitivity analysis with parameter values of 0.01 and 0.04 .

\subsection{Incorporating Alternative Cross Country Fairness Based Approaches to Global Emissions Reductions}

We use the model to analyze different counterfactuals relative to the BAU scenario and these reflect the various fairness approaches to emission reductions. As discussed earlier one is that from the global capacity constraint on emissions implied by a temperature change target (say $2^{\circ} \mathrm{C}$ ) that the emissions to be allocated on an equal per capita basis. These 
allocations may or may not take into account historical emissions by country. Another is that the temperature change benefit to other countries created through a country's emission reduction (net of abatement costs) should be equallised per capita globally. Yet another is to allow for equal per capita costs to countries making emission reductions. Developing countries can also be compensated (as agreed under CBDR) for forgone development via financial transfers; or domestic producers in participating countries can be compensated via a setting of trade measures for loss of competitiveness due to non participation in global climate policy by non joining parties.

In doing this, the model can be extended to capture border tax adjustments, tariffs, and financial transfers as penalties or inducements to participate in negotiations. The size of transfers, either as a percentage of recipient country GDP or of donating country GDP, or as an amount in $\$$ transferred from developed countries is taken as exogenous, but can be varied in sensitivity analyses. Tariffs and border adjustments apply to the prices of goods crossing national borders and generate revenues and are considered in Tian and Whalley(2010). Trade imbalances (including transfers) are exogenous in the model.

\section{Data and Model Calibration}

We calibrate the model set out above both to a temperature change function for prospective changes in temperature under business as usual scenarios out to 2020,2030 and 2050 and to preferences given damage estimates for climate change in a BAU scenario. These time periods correspond to possible commitment periods in a potential global agreement. We construct a BAU growth profile using forward projections of 2006 data, and model calibration to this profile determines key model parameters. In performing these calibrations we use varying estimates of associated damage in the ranges reported by Stern (2006) and Mendelsohn (2007) and abatement cost estimates as in Stern (2006). We use an 8 country grouping, of Brazil, Russia, India, China, US, EU, Japan, and the Rest of the World (ROW).

\subsection{The Base Case Scenario Data Sources}

We use GDP growth as the measure of change in potential consumption by country over 
the various periods of analysis. China, India, Russia, Brazil, USA, EU, Japan and the Rest of the World (Row) are assumed to have BAU growth rates of $0.09,0.07,0.07,0.0320 .026,0.020,0.17$, and 0.30 respectively, given by average growth rates of 2000 to 2006 (data from World Bank website). We then use the BAU growth path data to calibrate the temperature change function using estimated BAU temperature change estimate over the period from key literature sources, including Stern (2006) and Mendelsohn (2007). This implies that in high growth scenarios emissions are larger and also temperature change is higher.

Table 1 reports the 2006 output and emissions data used in our period projections for the base case, and the growth rates used. Preferences towards goods and temperature change are determined for each country using alternative damage estimates from the same sources.

Table1 BAU Total Output, Emission, and Emission Intensity Data and Growth Rates Assumed out to 2050

\begin{tabular}{|c|c|c|c|c|c|c|c|c|c|}
\hline & China & India & Russia & Brazil & U.S & E.U. & Japan & ROW & Total \\
\hline Output in 2006, trill\$ & 2.65 & 0.91 & 0.99 & 1.07 & 13.16 & 10.64 & 4.37 & 14.68 & 48.47 \\
\hline Emission intensity 2006 & 2.22 & 2.01 & 2.58 & 0.50 & 0.52 & 0.29 & 0.27 & 0.98 & \\
\hline Emission in 2006, bmt & 5.88 & 1.83 & 2.54 & 0.53 & 6.81 & 3.13 & 1.19 & 14.37 & 36.28 \\
\hline $\begin{array}{l}\text { Population projection by } \\
\qquad 2050 \text { (million) * }\end{array}$ & 1449.42 & 1601.01 & 118.23 & 228.43 & 420.08 & 331.307 & 99.89 & 4503.88 & 8752.247 \\
\hline $\begin{array}{l}\text { Cumultive Emission } \\
\text { 1990-2006, bmt }\end{array}$ & 98.59 & 27.90 & 93.77 & 10.00 & 327.34 & 328.55 & 45.11 & 196.50 & 1127.76 \\
\hline $\begin{array}{l}\text { Emission projection } \\
\text { 2006-2050, bmt }\end{array}$ & 4007.35 & 627.53 & 488.17 & 59.23 & 659.39 & 274.37 & 104.73 & 1715.09 & 7935.86 \\
\hline $\begin{array}{l}\text { Cum. Emission } \\
\text { 1990-2050, bmt }\end{array}$ & 4105.94 & 655.43 & 581.94 & 69.47 & 987.26 & 605.7 & 150.17 & 1917.76 & 9440.82 \\
\hline
\end{tabular}

Sources: World Bank Dataset and authors calculations

\subsection{Calibration of Model Parameters}

In calibration, we use data on consumption and trade for OECD and non-OECD economies along with country growth profiles and various damage and temperature change assumptions as business as usual (BAU) scenarios. We undertake numerical investigation with our analytical 
structure using calibration to determine model parameters values followed by counterfactual analyses of various forms. The base data we use are for 3 different periods 2006-2030 and 2006-2050 with assumed yearly growth rates over the period.

We first discuss the calibration of preference parameters. According to the Stern Review (2005), Mendelssohn (2006) and other literature, on BAU paths the damage costs from emissions range from 1 to $20 \%$ of GDP out to 2050 . We treat damage from climate change in the model as utility change of the same proportion over the same time and use it to calibrate the preference parameters in the model.

Without temperature change, the utility change function is:

$$
U_{i}^{*}=C_{i}
$$

And with damage we have :

$$
U_{i}^{*} / U_{i}=\left(\frac{H-\Delta T}{H}\right)^{\beta}
$$

With temperature change, there will thus be a utility change loss from damage. We can thus calibrate $\beta$ using equation (14) above for given different values of $\mathrm{H}$. For illustrative purposes, in Table 2 we report calibrated $\beta$ values for a time period of 50 years as the base case. In our simulation analysis, we use $\mathrm{H}=10$ as the base case, and perform sensitivity analysis with $\mathrm{H}=20$ and $\mathrm{H}=30$.

The temperature change function is written as a function of emission changes over the same period, and we treat it as a power function of total emission (not output) change for the world. Based on the discussion in Stern (2006), we assume the BAU path of emissions will lead to about 3 degree temperature increase around the year 2030, and near to 5 degrees by around 2050. For simplicity, we assume that zero growth in the global economy will lead to no temperature change.

$$
\Delta T=a\left(\sum_{i} \Delta E_{i}\right)^{b}
$$

With data on growth rates and emission intensities for each country under the BAU growth scenarios, we can then calibrate the parameters a and b. We have data for year 2006 and projections of emissions and output data for 2030 and 2050. We choose 2006 as the base year, and assume that 25 years later, that is by 2030 , the global average temperature will increase by 3 degrees, and 5 degrees by 2050. We assume that the BAU path implies output growth for each 
country comparable to that of 2000-2006, while emission intensities are unchanged from the year 2006. Table 2 reports the calibrated values of $a$ and $b .^{6}$

We are able to relax these assumptions to allow for autonomous (exogenous) improvements in energy efficiency (intensity) over time.

Table 2 Calibrated Model Parameters

\begin{tabular}{|c|c|c|c|}
\hline \multirow[b]{2}{*}{$\mathrm{H}$} & \multicolumn{2}{|l|}{$\beta$ in preferences } & \multirow{2}{*}{$\begin{array}{c}a, b \text { in temperature change } \\
\text { function assuming } 50 \text { year time } \\
\text { horizon }\end{array}$} \\
\hline & $\begin{array}{l}\text { BAU Damage cost } \\
\text { assumed }\end{array}$ & $\beta$ & \\
\hline \multirow{3}{*}{10} & $10 \%$ & 0.152 & \multirow{5}{*}{$\begin{array}{l}\Delta T^{2030}=3 \\
\Delta T^{2050}=5\end{array}$} \\
\hline & $20 \%$ & 0.322 & \\
\hline & $50 \%$ & 1.000 & \\
\hline \multirow{3}{*}{20} & $10 \%$ & 0.366 & \\
\hline & $20 \%$ & 0.776 & \\
\hline & $25 \%$ & 1.000 & \multirow{3}{*}{$\begin{array}{c}a=0.00015 \\
b=0.656\end{array}$} \\
\hline \multirow{2}{*}{30} & $10 \%$ & 0.578 & \\
\hline & $16.7 \%$ & 1.000 & \\
\hline
\end{tabular}

Source: authors' calculations

\section{Model Results}

We analyze the implications of alternative cross country fairness considerations entering multicounty emissions reductions by first calibrating our model to our base period BAU scenario data for the single period 2006-2050, and then performing counterfactual experiments which incorporate a series of alternative emissions reductions. Each of these captures different fairness approaches and arrangements.

Table 5.1 sets out the base case (BAU) projected cumulative emissions by country as well as the emissions implied by each of four cross country fairness approaches and uniform equiproportional reductions in annual emissions for comparative purposes. These are then each applied in the model as a scenario in which the global emission reduction is that projected as

\footnotetext{
${ }^{6}$ Given the Stern estimates, $b<1$ which implies diminishing not increasing impacts of growing consumption on temperature change.
} 
required to meet a global temperature change target of $2^{\circ} \mathrm{C}$. BAU cumulative emissions globally for the period 2006-2050 are 7935.86 equivalent of carbon. To meet a $2^{\circ} \mathrm{C}$ temperature change target globally, we adopt the target from Nordhaus (2010) of 376.73 billions of metric tons of carbon $^{7}$ (equivalent 1382.60 billion metric tons of $\mathrm{CO} 2$ ) for limiting global warning to $2 \mathrm{C}$.

We use alternative country allocation schemes based on the fairness considerations discussed in the earlier sections of the paper to calculate implied emission reductions reported in Table 3 as follow:

a) That the global emissions target and emissions allocation by country is based on an equal per capita allocation of absorptive capacity in the atmosphere across the world. These are calculated both with and without emissions of historical responsibility for emissions.

b) That the emission allocation instead is one where the benefits to other countries than the country making the cuts are equal on a per capita basis for the country making the cuts.

c) That the costs to countries making the cuts are equal on a per capita basis. We also consider cases where there are financial transfers between developed and developing countries.

Table 3 reports differences in the country allocation of emissions reductions among these approaches. The uniform equi-proportional cut is that implied by Table 1 to meet the target of a $2^{\circ} \mathrm{C}$ change in temperature by 2050 . The equal per capita capacity cuts are those giving equal emissions per person across all countries consistent with the same target. These calculations are made both taking account of emissions by country prior to 2012, and not taking these into account. Equal per capita benefit allocations involve model calculations of benefits to other countries of reduction divided by populations of other countries. Equal burden per capita for reductions calculates money metric utility costs divided by the populations of the country making the cuts. These reductions vary greatly both by country and for some countries across cases. The high growth rates for China compounded out to 2050 account for their large shares of reductions. On an equal emissions capacity per capita basis, these range from $33.61 \%$ for Brazil to $98.85 \%$ for Russia. Total world population is 8752.25 million, and total world cumulative emissions are

\footnotetext{
${ }^{7}$ Nordhaus uses GTC as the units, which are the same as billions of metric tons of carbon.
} 
9440.82, with an average emission per person in the world of 1.079. Considering the large population in the future and the small emission stock in history, China and India, receive more space to emit ( $17.64 \%$ and $20.46 \%$ of the total in Table 5.1 ), while Russia receives only $0.41 \%$ due to its small population in 2050.

These distributions are reversed when the alternative fairness criteria are applied. When equal per capita benefits are used, the per capita contributions to the world of China, India, Russia, Brazil, USA, EU, Japan and the Rest of the World (Row) are separately 0,005, 0,0057, $0.0832,0.0655,0.0171,0.0258,0.1118$ and 0.0017 . Japan is given more emission space due to its high per capita benefit contribution to the world. When equal per capita burdens are considered, per capita costs of China, India, Russia, Brazil, USA, EU, Japan and the Rest of the World (Row) are separately $0.0028,0.0052,0.0480,0.1622,0.0731,0.1477,0.5072$ and 0.0030 . Japan again is given more emission space due to its high per capita burden.

In Table 3, due to both China and US's dominant carbon emission position in the long run (almost half of the world), how emission targets are allocated has limited impact on these two countries' potential emissions reduction commitments. Both need to cut around $95 \%$ under the various allocation assumptions. These do, however, have different impacts on other developed countries, including EU and Japan and other emerging economies' reduction commitments (including India, Brazil and Russia). For example, when allocated emission targets are set in terms of equal per capita emission capacity for the world, India and Brazil's reduction targets contract by nearly half (compared to the other two forms of allocation). When the emission targets are allocated in terms of equal per capita benefit for the world, Russia and Japan benefit with more emission space allocated, while India and Brazil lose, and China, US and EU are negatively affected. When equal per capita burdens are considered as the basis to allocate emission targets, almost all BRIC countries lose, and most developed countries benefit, except for the US. 
Table 3 Country Emission Reductions to Meet a $2^{\circ} \mathrm{C}$ target by 2050 Corresponding to Different Fairness Considerations

\begin{tabular}{|c|c|c|c|c|c|c|c|c|c|c|}
\hline & \multicolumn{5}{|c|}{$\begin{array}{l}\text { Emission allocation by country out to } 2050 \text { under alternative approaches } \\
\qquad \text { (Bmt carbon equivalent) }\end{array}$} & \multicolumn{5}{|c|}{$\%$ emission reduction by country out to 2050} \\
\hline & $\begin{array}{c}\text { Uniform } \\
\text { equal } \\
\text { proportional } \\
\text { cuts } \\
(82.58 \%)\end{array}$ & $\begin{array}{c}\text { equal-per } \\
\text { capita capacity } \\
\text { without } \\
\text { history } \\
\text { considerations }\end{array}$ & $\begin{array}{c}\text { equal-per } \\
\text { capita } \\
\text { capacity with } \\
\text { history } \\
\text { considerations }\end{array}$ & $\begin{array}{l}\text { equal per } \\
\text { capita } \\
\text { benefits } \\
\text { of } \\
\text { reductions }\end{array}$ & $\begin{array}{l}\text { equal per } \\
\text { capita } \\
\text { burdens of } \\
\text { reductions }\end{array}$ & $\begin{array}{c}\text { Uniform } \\
\text { equal } \\
\text { proportional }\end{array}$ & $\begin{array}{c}\text { equal-per } \\
\text { capita capacity } \\
\text { without } \\
\text { history } \\
\text { considerations }\end{array}$ & $\begin{array}{c}\text { equal-per } \\
\text { capita } \\
\text { capacity with } \\
\text { history } \\
\text { considerations }\end{array}$ & $\begin{array}{l}\text { equal per } \\
\text { capita } \\
\text { benefit of } \\
\text { reductions }\end{array}$ & $\begin{array}{l}\text { equal per } \\
\text { capita } \\
\text { burden of } \\
\text { reductions }\end{array}$ \\
\hline China & 698.08 & 228.97 & 243.93 & 21.88 & 4.1 & $82.58 \%$ & $94.29 \%$ & $93.91 \%$ & $98.42 \%$ & $99.70 \%$ \\
\hline India & 109.32 & 252.91 & 282.93 & 25.12 & 7.51 & $82.58 \%$ & $59.70 \%$ & $54.91 \%$ & $98.18 \%$ & $99.46 \%$ \\
\hline Russia & 85.04 & 18.68 & 5.62 & 364.1 & 69.97 & $82.58 \%$ & $96.17 \%$ & $98.85 \%$ & $73.67 \%$ & $94.94 \%$ \\
\hline Brazil & 10.32 & 36.09 & 39.33 & 286.66 & 236.25 & $82.58 \%$ & $39.08 \%$ & $33.61 \%$ & $79.27 \%$ & $82.91 \%$ \\
\hline US & 114.87 & 66.36 & 20.86 & 74.97 & 106.54 & $82.58 \%$ & $89.94 \%$ & $96.84 \%$ & $94.58 \%$ & $92.29 \%$ \\
\hline EU & 47.80 & 52.34 & 4.34 & 112.96 & 215.1 & $82.58 \%$ & $80.92 \%$ & $98.42 \%$ & $91.83 \%$ & $84.44 \%$ \\
\hline Japan & 18.24 & 15.78 & 10.38 & 489.55 & 738.82 & $82.58 \%$ & $84.93 \%$ & $90.09 \%$ & $64.59 \%$ & $46.56 \%$ \\
\hline Row & 298.77 & 711.48 & 775.23 & 7.36 & 4.31 & $82.58 \%$ & $58.52 \%$ & $54.80 \%$ & $99.47 \%$ & $99.69 \%$ \\
\hline world & 1382.60 & 1382.60 & 1382.60 & 1382.60 & 1382.60 & $82.58 \%$ & $82.58 \%$ & $82.58 \%$ & $82.58 \%$ & $82.58 \%$ \\
\hline
\end{tabular}

Source: Authors calculations base on Table 1 
Table 4 Country welfare impacts by country with and without emission historic considerations

(all for 2 degree target and as \% of BAU case)

Money Metric Equivalents in Billion \$

\begin{tabular}{|c|c|c|c|}
\hline & $\begin{array}{l}\text { Uniform equal } \\
\text { proportional }\end{array}$ & $\begin{array}{l}\text { Equal-per capita emission } \\
\text { capacity with history } \\
\text { considerations }\end{array}$ & $\begin{array}{l}\text { Equal-per capita emission } \\
\text { capacity without history } \\
\text { considerations }\end{array}$ \\
\hline China & $\begin{array}{l}-2475.56 \\
(-1.37 \%)\end{array}$ & $\begin{array}{c}-4923.969 \\
(-2.74 \%)\end{array}$ & $\begin{array}{l}-5001.79 \\
(-2.77 \%)\end{array}$ \\
\hline India & $\begin{array}{l}-25.857 \\
(-0.09 \%)\end{array}$ & $\begin{array}{c}1609.564 \\
(5.93 \%)\end{array}$ & $\begin{array}{l}1337.49 \\
(4.93 \%)\end{array}$ \\
\hline Russia & $\begin{array}{l}-326.052 \\
(-1.57 \%)\end{array}$ & $\begin{array}{l}-813.112 \\
(-3.89 \%)\end{array}$ & $\begin{array}{l}-733.79 \\
(-3.51 \%)\end{array}$ \\
\hline Brazil & $\begin{array}{l}-164.837 \\
(-12.46 \%)\end{array}$ & $\begin{array}{l}926.367 \\
(7.03 \%)\end{array}$ & $\begin{array}{c}804.24 \\
(6.11 \%)\end{array}$ \\
\hline US & $\begin{array}{c}4379.737 \\
(4.59 \%)\end{array}$ & $\begin{array}{l}-210.720 \\
(-0.22 \%)\end{array}$ & $\begin{array}{l}-296.21 \\
(-0.32 \%)\end{array}$ \\
\hline EU & $\begin{array}{c}2981.634 \\
(3.51 \%)\end{array}$ & $\begin{array}{c}-1594.123 \\
(-1.88 \%)\end{array}$ & $\begin{array}{l}-1871.62 \\
(-2.22 \%)\end{array}$ \\
\hline Japan & $\begin{array}{c}38.577 \\
(0.098 \%)\end{array}$ & $\begin{array}{l}-688.322 \\
(-1.76 \%)\end{array}$ & $\begin{array}{l}-706.13 \\
(-1.81 \%)\end{array}$ \\
\hline Row & $\begin{array}{c}-2998.304 \\
(-1.66 \%)\end{array}$ & $\begin{array}{c}4709.347 \\
(2.60 \%)\end{array}$ & $\begin{array}{l}3710.08 \\
(2.05 \%)\end{array}$ \\
\hline
\end{tabular}

Source: Authors calculations

In Table 4 we report model calculations of the welfare impacts of emissions reductions based on equal per capita allocations of atmosphere absorptive capacity across regions. These are calculated both with and without adjustments for historical responsibility. These are money metric measures in US\$ for the period 2012-2050. Relative to eqiproportional reductions, welfare impacts over the commitments periods change sharply using these fairness criteria. Significant gains for the US and EU under uniform eqiproportional reductions become significant losses. Losses for China increases further, and small losses for India, and Brazil become significant gains. Differences with history considerations added are small since the majority of emissions out to 2050 occur after 2006.

Table 5 reports the welfare impacts by country for reductions over the period $2006-2050$ based on equal per capita benefits and equal per capita burdens with the equiproportional 
reductions case again reported for comparative purpose. Losses for China increase, with a similar outcome for India and Russia. Japan is a large gainer in all cases. We report Hicksian equivalent variations in \$trillion, and also report these as a \% of BAU base case discounted income between 2006 and 2050.

Table 5 Country Welfare Impacts of Further Fairness Approaches

(all for $\mathbf{2}$ degree target and as \% of BAU case)

Money Metric Equivalents in Billion \$

\begin{tabular}{|c|c|c|c|c|}
\hline \multirow{2}{*}{ China } & $\begin{array}{c}\text { Assumed equal-proportional } \\
\text { emission }\end{array}$ & $\begin{array}{c}\text { Assumed equal-per } \\
\text { capita emission*** }\end{array}$ & $\begin{array}{c}\text { Assumed equal per } \\
\text { capita benefit }\end{array}$ & $\begin{array}{c}\text { Assumed equal per } \\
\text { capita burden }\end{array}$ \\
\hline \multirow{2}{*}{ India } & -2475.56 & -4923.969 & -5559.365 & -5607.69 \\
& $(-1.37 \%)$ & $(-2.74 \%)$ & $(-3.11 \%)$ \\
\hline \multirow{2}{*}{ Russia } & -25.857 & 1609.564 & -934.596 & -1109.92 \\
& $(-0.09 \%)$ & $(5.93 \%)$ & $(-2.99 \%)$ & -260.812 \\
\hline \multirow{2}{*}{ Brazil } & -326.052 & -813.112 & $1493)$ \\
& $(-1.57 \%)$ & $(-3.89 \%)$ & $(7.89 \%)$ & $(-1.38 \%)$ \\
\hline \multirow{2}{*}{ US } & -164.837 & 926.367 & 1035.013 & $(7.135 \%)$ \\
\hline \multirow{2}{*}{ EU } & $(-12.46 \%)$ & $(7.03 \%)$ & -1547.544 & -729.861 \\
& 4379.737 & -210.720 & $(-1.22 \%)$ & $(-0.58 \%)$ \\
\hline \multirow{2}{*}{ Japan } & $(4.59 \%)$ & $(-0.22 \%)$ & 3032.892 & 4227.683 \\
& 2981.634 & -1594.123 & $(3.21 \%)$ & $(8.70 \%)$ \\
\hline
\end{tabular}

$* * *$ : per capita emission with history considerations

Source: Authors calculations

Table 6 reports model calculations of the required financial transfers to the different larger developing countries in the model needed as to compensate them for any losses incurred when undertaking the emissions reductions set out in Table 3. The financial transfers to China of nearly $\$ 11$ trillion exceed the negative welfare impacts in Table 3, since the welfare impacts include the money metric equivalent welfare gain through preferences from temperature change reduction. 
Table 6 Compensating Financial Transfers to Developing Countries Corresponding to Different Fairness Criteria (all for $2^{\circ} \mathrm{C}$ target)

(Money Metric Equivalents in Billion \$)

\begin{tabular}{|c|c|c|c|}
\hline China & $\begin{array}{c}\text { Equal-per capita emission } \\
\text { capacity*** }\end{array}$ & $\begin{array}{c}\text { Equal per capita } \\
\text { benefit }\end{array}$ & $\begin{array}{c}\text { Eequal per capita } \\
\text { burden }\end{array}$ \\
\hline India & 10950 & 10770 & 10815 \\
\hline Russia & - & 1083 & 1305 \\
\hline Brazil & 1650 & - & 525 \\
\hline
\end{tabular}

***: per capita with history considerations

In Table 7, we also report sensitivity analysis results for the size of financial transfers required to compensate developing countries for losses from emissions reductions when changing the fairness criteria used. The transfers emerge from this Table as relatively insensitive.

Table 7 Sensitivity Analysis of Financial Transfers to Compensate Developing Countries Corresponding to Different Fairness Criteria in Emission Allocations

(Money Metric Equivalents in Billion \$)

\begin{tabular}{|c|c|c|c|c|c|c|c|c|}
\hline & & \multicolumn{2}{|c|}{$\begin{array}{c}\text { Equal per capita emission } \\
\text { capacity*** }\end{array}$} & \multicolumn{2}{|c|}{ Equal per capita benefit } & \multicolumn{3}{|c|}{ Equal per capita burden } \\
\hline & & China & Russia & China & India & China & India & Russia \\
\hline \multirow{2}{*}{$\begin{array}{c}\text { Assumed } \\
\text { discount rate }\end{array}$} & BAU & 10950 & 1650 & 10770 & 1083 & 10815 & 1305 & 525 \\
\hline & $1 \% / 0.5 \%$ & 15320 & 1985 & 13785 & 1665 & 13950 & 1875 & 870 \\
\hline \multirow{2}{*}{$\begin{array}{c}\text { Utility } \\
\text { damage from } \\
\text { BAU }\end{array}$} & $10 \%$ & 10950 & 1650 & 10770 & 1083 & 10815 & 1305 & 525 \\
\hline & $5 \%$ & 27730 & 4850 & 30255 & 3960 & 31085 & 4215 & 1505 \\
\hline
\end{tabular}

***: per capita with history consideration 
Table 8 reports model results which show the impacts of changing the basis for calculating emissions reductions from production of emissions to emissions implied by consumption under each of the fairness criteria. The impacts are small for most regions, except for the US where the trade imbalance is large.

Finally Table 9 reports sensitivity analyses for the results in Table 3. These involve alternative settings for underlying BAU scenario assumptions and model parameters. We report impacts of changes in assumed energy efficiency improvement growth rates, assumed discount rates, assumed utility damage from climate change in the BAU case, and also the use of PPP measures to calibrate base case GDP and income over the period 2006-2050. The latter imply large differences in the data used to represent the relative size of China and India and impacts for these countries change accordingly. Results also indicate potential significant sensitivity in results when damage and discount rate parameters vary. 
Table 8 Welfare Impacts for Changed Bases for Reductions in Emissions Reduction Based on country Consumption Rather Than Production

\section{(Money Metric Equivalents in Billion \$)}

\begin{tabular}{|c|c|c|c|c|c|c|c|c|c|}
\hline & & China & India & Russia & Brazil & U.S & E.U. & Japan & ROW \\
\hline \multirow{2}{*}{$\begin{array}{c}\text { Under } \\
\text { equal per } \\
\text { capita } \\
\text { capacity }\end{array}$} & Central case $* * *$ & -4923.97 & 1609.564 & -813.112 & 926.367 & -210.72 & -1594.12 & -688.322 & 4709.347 \\
\hline & $\begin{array}{l}\text { Consumption } \\
\text { not production }\end{array}$ & -5193.696 & 1405.127 & -780.346 & 901.242 & -1301.867 & -2209.772 & -803.514 & 4720.696 \\
\hline \multirow{2}{*}{$\begin{array}{c}\text { Under } \\
\text { equal per } \\
\text { capita } \\
\text { benefit }\end{array}$} & Central case & -5559.37 & -934.596 & 1493.709 & 10358.01 & -1547.54 & 3032.892 & 24333.26 & -6117.09 \\
\hline & $\begin{array}{l}\text { Consumption } \\
\text { not production }\end{array}$ & -5811.948 & -1158.771 & 1515.363 & 10324.801 & -3045.939 & 2303.032 & 24217.555 & -6053.651 \\
\hline \multirow{2}{*}{$\begin{array}{c}\text { Under } \\
\text { equal per } \\
\text { capita cost }\end{array}$} & Central case & -5607.69 & -1109.92 & -260.812 & 8452.063 & -729.861 & 8227.683 & 37333.89 & -6070.4 \\
\hline & $\begin{array}{l}\text { Consumption } \\
\text { not production }\end{array}$ & -5880.830 & -1329.261 & -235.283 & 8419.343 & -2170.464 & 7511.484 & 37215.709 & -6040.709 \\
\hline
\end{tabular}


Table 9 Sensitivity of Table 3 Results to Key BAU Scenario Assumptions

(Money Metric Equivalents in Billion \$)

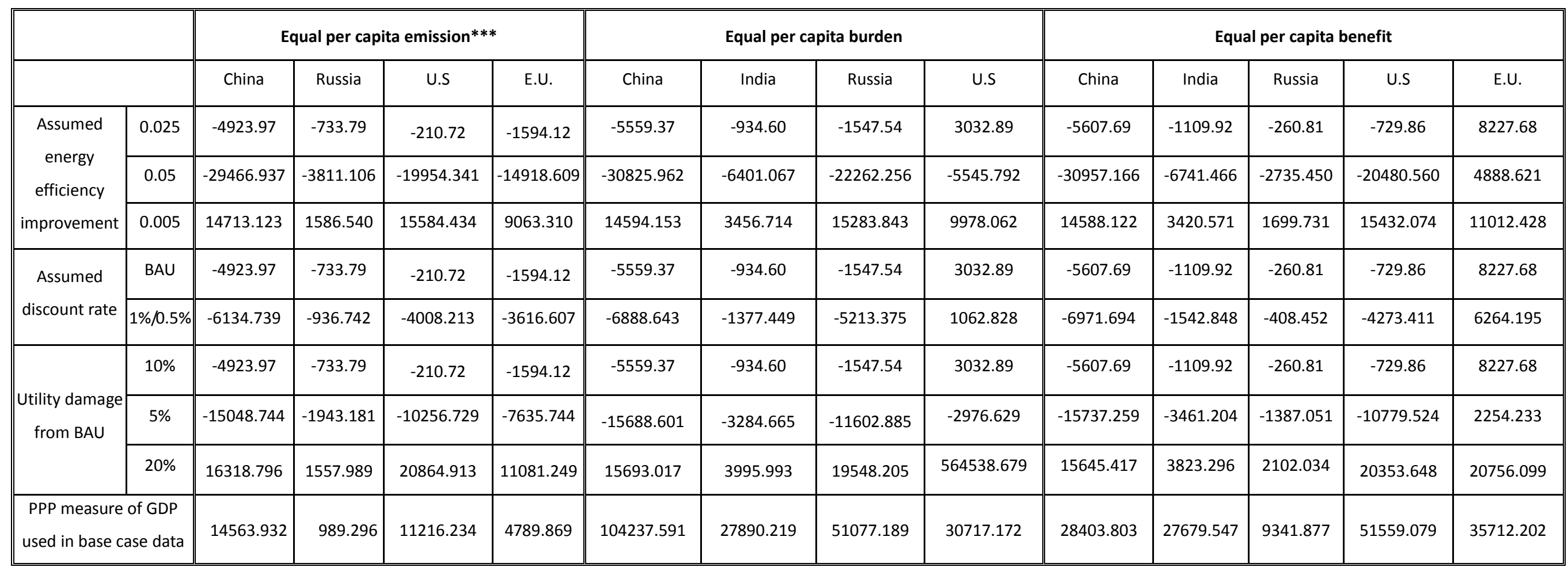

***: per capita with history consideration 


\section{Concluding Remarks}

Negotiations on a global climate policy regime to follow on after the Kyoto Protocol in 2012 represent a size and form of social engineering on a global scale way beyond anything previously attempted in trade and finance. As such they will inevitably be difficult to conclude in a single comprehensive effort. The UNFCCC process has made the successful conclusion of these negotiations even more problematic by first restricting negotiations to relatively similar developed countries in Kyoto, and then attempting to add poorer countries with divergent characteristics in a second stage. These range from fast growing large manufacturing based economics, such as China, to poor low growth economies in Africa. Not surprising a homogeneous treatment faces difficulties in achieving consensus.

Here we use a calibrated global model of consumption, production and trade with climate change entering preferences to investigate the potential differing impacts of alternative approaches to these negotiations based on fairness arguments used to allocate country emissions reductions. Due to China and the US's dominant carbon emission position in the long run, how emission targets are allocated has limited impact on these two countries' potential emission reduction commitments, but they do have potentially sharply impacts both on other developed countries, including EU and Japan and other emerging economies commitments (including India, Brazil and Russia). Equal per capita allocations of emission capacity hurts the US and the EU relative to proportional cuts, and also hurts China in the BAU scenario due to China's compounding growth out to 2050. When equal per capita burdens are considered as the basis to allocate emission targets, most BRIC countries lose, and most developed countries benefit, except for the US. These levels suggest larger differences in impacts, and hence that fairness debate on country emissions reductions allocations will continue. If damage is predicted to increase sharply, so that joint gains for negotiations increase, then more progress may occur. 


\section{References}

Allen et al. 2009, "Warming caused by cumulative carbon emission: the trillionth tone", Nature, 458 (7242): 1163-1166 DOI: 10.1038/nature08019

Cai, Yuezhou and Riezman, R. and Whalley, J., 2009, "International trade and the negotiability of global climate change agreements," NBER working paper 14711, http://www.nber.org/papers/w14711

Dasgupta, P.S., 2008, “Discounting climate change," Journal of Risk and Uncertainty, Vol. 37, pages 141-169.

Goulder, L.H., Mathai, K., 2000, Optimal CO2 abatement in the presence of induced technological change. Journal of Environmental Resource Economics 39 (1), $1-38$.

Mendelsohn, R. O., 2006, “A critique of the Stern Report,” Regulation, Vol. 29, No. 4., Winter 2006-2007.

Meinshausen et al. 2009, "Greenhouse-gas emission targets for limiting global warming to $2{ }^{\circ} \mathrm{C} "$, Nature, 458 (7242): 1158-1162 DOI: 10.1038/nature08017

Nordhaus, W.,1990, "To Slow or Not to Slow: The Economics of the Greenhouse Effect". Yale University Press, New Haven, CT. Nordhaus, W. (1994).

Stern, H. H., 2006, "Stern Review on the Economics of Climate Change", London, UK: Her Majesty's Treasury.

Tian, Huifang and Whalley, J., 2008, “China's participation in global environmental negotiations," NBER Working Paper 14460.

Tian, Huifang and Whalley, J., 2010, "Trade sanctions, financial transfers and BRIC participation in global climate change negotiations", Journal of Policy Modeling, Volume 32, Issue 1, Pages 1-162 (January-February 2010).

Uzawa, H., 2004, Economic Theory and Global Warming, Cambridge University Press.

Weitzman, M. L., 2007, “A review of the Stern Review on the Economics of Climate Change," Journal of Economic Literature, Vol. 45 (3), pages 703-724. 